\title{
A Study of Ba Jin (李尧棠) in Chinese Electronic Media*
}

\author{
WANG Miao-miao \\ North China Electric Power University, Beijing, China
}

\begin{abstract}
This paper gives an outline of the core concerns in Chinese Electronic Media, according to the data collection of the webpage about $\mathrm{Ba}$ Jin in Chinese, exploring what is happening to $\mathrm{Ba}$ Jin on the Chinese Internet in China, including the developments on the introductions to Ba Jin; the biographies of his; the works of his, which takes Turbulent Current Trilogy as an example; as well as politics, especially on anarchism and populism; and images of the female, etc. Besides, it discusses how the criticism and reception of Ba Jin's works online in Chinese are different from those in English in the U.S-America. The paper also analyzes the hidden reasons, most of which are owing to the specific historical and theoretical values, expecting to provide necessary reference for a global understanding and appreciation of Ba Jin’s works, to contribute to promotions to study of Ba home and abroad.
\end{abstract}

Keywords: Ba Jin, electronic media, China, the U.S.

\section{Introduction}

Ba Jin (Li Yaotang, 1904-2005), is known as one of the six most influential writers in modern Chinese literature (the others are Lu Xun, Guo Moruo, Mao Dun, Lao She, and Cao Yu). For his outstanding contributions to the modern Chinese literature, he also leads an important position in Chinese Electronic Media (Internet Literature/Digital humanities). "Digital humanities...is about...the negotiation of culture(s) -in theory and application —and how cultural practices shape the use of (new) media and their social significance." And "the world wide web is the natural venue in which to find, to interact with, and to get to know "the other". (See, Tötösy de Zepetnek and Graciela Boruszko, $<$ http://stateofthediscipline.acla.org/entry/paradigm-shift-comparative-humanities-digital-humanitiespedagogynew-media-technology-and $>$ ). As to electronic literature, N. Katherine Hayles defines it as "generally considered to exclude print literature that has been digitized, is by contrast 'digital born', and (usually) meant to be read on a computer" ( $<$ http://eliterature.org/pad/elp.html $>$ ). As the world's largest search engine in Chinese, Baidu (百度) (wwww.baidu.com), which was founded in Zhong Guancun, Beijing, China, in January 2000 by $\mathrm{Li}$ Yanhong and $\mathrm{Xu}$ Yong, stores up more than hundred billion Chinese webpage databases. Therefore, this paper takes related Chinese electronic information found via Baidu as the basis of the study of Ba. And in Baidu Encyclopedia, "electronic media" is defined as: "a kind of media to advertise and promote through the advanced electronic information technology on the base of certain electronic means.” “电子媒体是以一定的

\footnotetext{
* Acknowledgements: The research for this paper was funded by 中国博士后科学基金第 59 批面上资助项目 (China Postdoctoral Science Foundation funded project, Project No. 2016M590884) \&中央高校基本科研业务费专项资金资助 (Fundamental ResearchFunds for Central Universities, Project No. 2017MS084).

WANG Miao-miao, Ph.D., Associate Professor, English Faculty, North China Electric Power University, Beijing, China.
} 
电子手段，通过先进的电子信息技术来进行广告宣传的媒体。”) (http://baike.baidu.com/link?url=KXRJKs_l3xnXo8RnyNH3I7ELvGG-PR87I9QnJ70GdObAn2Nowc3umTY wKsgQEbzpEk4Mdx35yZwEwrUj4Ghr8)

This paper collects certain data on Ba from the Chinese webpage, expecting to give an outline of the core concerns of what is happening to Ba on Internet in Chinese in China, to illustrate its related development at different stages, including developments on the introductions to $\mathrm{Ba}$; thebiographies of $\mathrm{Ba}$; the works of $\mathrm{Ba}$, which takes Turbulent Current Trilogy as the example; politics, especially on anarchism and populism; and images of the female, etc. Besides, this paper also discusses how the criticism and reception of Ba online in China are different from those in the US-America, with the analysis of the hidden reasons, most of which are owing to the specific historical and theoretical values. To a certain extent, the study of Ba in Chinese Electronic Media takes literariness as the core, and reflects the cognition status on $\mathrm{Ba}$ in contemporary civil society. Meanwhile, it also demonstrates Ba's far-reaching influence on contemporary Chinese society and Chinese literature. This paper is expected to provide beneficial references for the transmission and reception of the survey and study of Ba in Chinese Electronic Media. Besides, it is also expected to contribute a lot to the study of Ba home and abroad.

\section{The Introductions to Ba Jin in Chinese Electronic Media}

To input the Chinese characters “the introduction to Ba Jin” (巴金简介) in Baidu, about 165,000 results can be got. (Up to June 26, 2016), which includes web page information in the formats of Adobe Acrobat PDF, Microsoft Word, Excel, Power Point, RTF, etc.

From the source of web page, information on the introduction to Ba Jin in Chinese are mainly as followings:

(1) From various celebrities' websites, such as: celebrities' website ( $<$ http://www.23yy.com/190000/188703.shtml $>$ ), with the title of Introduction to Ba Jin (巴金简介: 巴金的个 人 资 料 简 介 ) ; celebrities' resumes website (<http://www.gerenjianli.com/Mingren/01//mkrd2bkdk9spsi.html $>$ ), with the title of CV of Ba Jin (巴金简介); celebrities’ proverbs website (<http://www.mrzl.com/mrjs/wenhua/200602/mrjs 223.html $>$ ), with the title of Ba Jin, a famous writer. (巴金: 著名作家), etc.

(2) From Baidu information websites, such as: Baidu Encyclopedia (<http://baike.baidu.com/link?url=bU_Z9-x7ceIlYsqCdZ7kQDq0d4G3kCwd4pjvH_FlwSrGN--vhyFDrcnpXH eENx VqsZNgOo4pHoHnh-gSJYUK>), with the title of Ba Jin (巴金); Baidu academic website: (<http://xueshu.baidu.com/s?wd=paperuri:(4554c814ed0a22a61f45802c889aac20)\&filter=sc_long_sign\&sc_ks _para=q\%3D巴金先生简历 \&tn=SE_baiduxueshu_c1gjeupa\&ie=utf-8\&sc_us=6406463985443579767 >) with the title of the CV of Mr. Ba Jin (巴金先生简历); Baidu to Know: Ba Jin data and profile (http://zhidao.baidu.com/link?url=ndrsCYtXYhq_D43H1zsLfKy1H7Ouya7qSgpAV7fEJ3ldoQ6YDgP02YuH Uv-83idfxRGNWSDQQCv1z5khfIs4Hq), with the title of the information and introduction to Ba Jin; Baidu homework assistance: (http://www.zybang.com/question/3dd2b626f170aefaec3e6e827247b7ad.html), with the title of introduction to Ba Jin (巴金简介), etc.. 
(3) From various news columns in Chinese new media, such as: Sohu news column, with the title of references: Ba Jin (资料：巴金简历) (<http://news.sohu.com/20121128/n358933331.shtml $>$ ); Sina news center: Introduction to Ba Jin(巴金简介) ( $<$ http://news.sina.com.cn/c/2005-10-18/08457196338s.shtml $>)$; Net Ease news $\quad$ center: $\quad$ Ba $\quad \operatorname{Jin}(\quad$ 金

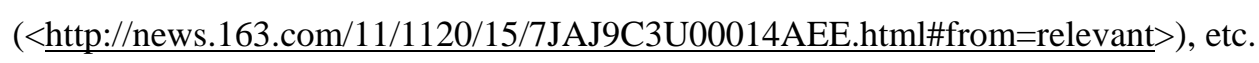

In addition, there are still a lot of webpage with information on the introduction to Ba Jin in the form of questions and answers, uploaded by individual users through blogs, or in the form of Office Microsoft, etc.

Judging from the title of each webpage, the topics are mainly as follows: Ba Jin; brief introduction to Ba Jin; Personal information about Ba Jin; the CV of Mr. Ba Jin; introduction and information on Ba Jin, etc. If click to enter each webpage to view the relevant details on the introduction to Ba Jin, it is mainly about: his Chinese name, his pseudonym, his birth and death dates, his nationality, his occupation, his nationality, his life story, his representative works, and his love and family.

This paper takes one of the most representative introductionsto Ba Jin as an example:

“Introduction to Ba Jin” (巴金), which ranks top one in "Baidu Encyclopedia”: “Ba Jin (November 25, 1904-October 17, 2005), originally names Li Yaotang, also with pseudonym as Peigan, Jile, Heilang and Chunfeng, and courtesy name Peigan. He is a native of Sichuan province with Han nationality, but from Jiaxing, Zhejiang province by descent. He is a Chinese writer, translator, social activist and non-party patriotic democrat. He was born in a feudal bureaucracy family in Chengdu, Sichuan province in November 1904. After the May Fourth Movement, Ba Jin was deeply influenced by new ideas, and began the individualanti feudal struggles. He left for Shanghai, Nanjing and other places to study in 1923, which marked the beginning of his semi-centennial literary career. The Collection of Random Thoughts, written by Ba Jin after the Cultural Revolution, was simple and sincere, but full of the author's confession and introspection in emotion. And Ba Jin was hailed as the "Conscience of Chinese literature in twentieth Century.

巴金（1904年11月25日一2005年10月17日），原名李尧棠，另有笔名有佩竿、极乐、黑浪、春风等，字蒂甘。 汉族，四川成都人，祖籍浙江嘉兴。中国作家、翻译家、社会活动家、无党派爱国民主人士。巴金1904年11月生 在四川成都一个封建官僚家庭里, 五四运动后, 巴金深受新潮思想的影响, 并在这种思想的影响下开始了他个人 的反封建斗争。1923年巴金离家赴上海、南京等地求学, 从此开始了他长达半个世纪的文学创作生涯。巴金在文 革后撰写的《随想录》，内容朴实、感情真挚，充满着作者的忓悔和自省，巴金因此被誉为“二十世纪中国文学的 良心。(<http://baike.baidu.com/view/1717.htm>)

Throughout the search results from Baidu, the information about the introduction to Ba Jin on each web page is abundant, either with thousands of words in detail, or only a brief summary with dozens of words. Besides, the major creators of the web information arecivilian, including scholars, who are specializing in the study of Ba Jin and professional writers, faculty members and journalists, especially for those who are specializing in paper work, government officials, enterprise managers, as well as students and individual hobbyists. Therefore, "the introduction to Ba Jin" in the electronic media or the network literature emerged in the background of the "post-modern society", is inheriting and exceeding the traditional literature as a new literary style with the features of civilian of major creators, diversity of creative methods, and strong interactivities, etc. Meanwhile, as Ouyang Youquan (欧阳友权) says in The Outline of Network Literature (网 络文学论纲): “In the existing situation of network literature, expansion of the quantity and the lack of the quality form a great contrast” (“在网络文学的现有格局中, 量的膨胀与质的欠缺形成了极大的反差”) 
(Ouyang, "Outline”, p. 412). ${ }^{1}$ The electronic media provides sample spaces for the exchange of ideas between media authors and readers, but it also needs further review and reflection, because of the arbitrariness of the will, the democracy of the knowledge, and the crisis of the representation of the hidden aesthetic value of art and humanistic spiritual value.

\section{The Biographies and Works of Ba Jin in Chinese Electronic Media}

In addition to "the introduction to Ba Jin" in Chinese electronic media, there are still more information on the biographies and works of Ba Jin. For the Chinese studies on the biographies of Ba Jin, the earliest publication must be the critical one. On September 23, 2015, China Social Science Network (<http://www.cssn.cn/wx/wx xdwx/201509/t20150923 2469084.shtml $>$ ) reported the earliest study on Ba Jin from a French scholar, called Jean Monsterleet (Ming Xingli), who came to China for missionary work. It is said that in 1950, the first biography of Ba Jin “Ba Jin’s Life and Works” (巴金的生活和著作) cwas published in China. This book was composed of partial translation of his doctoral dissertation. And it is mainly about an introduction to the life story and early works of Ba Jin. Meanwhile, Jean Monsterleet also captured some details about the exchange of ideas between Ba Jin's mother and those foreign missionaries, which was taken as one illustration on the philanthropism imparted to Ba Jin. What's more, due to the deeply influence of the estern culture, Jean Monsterleet also utilized the research method of comparative literature to do contrast and comparison on Ba Jin and foreign writers, like Romain Rolland, Malraux, etc. While the first critical biography of Ba Jin published by Chinese scholars was Critical Biography on Ba Jin (巴金评传), which was written by Chen Danchen (陈丹晨). This book systematically surveyed and commentedon Ba Jin's works and his experience in writing before 1979. It also focused on the relationship between Ba Jin and anarchism, which contributed a lot to the understanding of the early doublethink of Ba Jin. Moreover, another report from "Baidu to know", "On the Embodiment in the Two Core Issuesin Ba Jin's Works", (<http://zhidao.baidu.com/link?url=5q9Ur67nJnrGWVGIJ25Dftj5DiCiK2MrD_HWJTUw4I8LNpe-u5R9ELBh dgb_kJmlYIvFG2NS0hdNPDwGc5ACGWfVPXGiGOEVfaftZR0-Xmq>) again agrees that the biography from Chen Danchen is “the earliest works which adopted humanistic criticism since 1970s.” (新时期以来最早 采用人文批评的著作). Furthermore, among all those reported most on biographies of Ba Jin in Chines electronic media, there are Author Ba Jin (作家巴金) from Yu Simu (余思牧), The Biography of Ba Jin (作家 评传) from Li Cunguang (李存光), and Development of Personality: Biographyof Ba Jin (人格的发展: 巴金 传) from Chen Sihe (陈思和), etc.

The above biographical studies must be the most comprehensive and systematic on studies of Ba Jin's life story, his thought, the process of his literary creations, his works, and his personality spirit. And they also provide more broaden perspectives for readers to further read and interpret Ba Jin and his works.

As to the works of Ba Jin, 2,450,000 entries can be got from Baidu. Compared with the introduction and biography of Ba Jin, Chinese electronic media focuses more on his works. Since the publication of his first novella Perish (灭亡), Ba Jin has created more than 20 long-medium novels such as Love Trilogy (Fog, Rain, and Lightning), The Torrent Trilogy (Family, Spring, Autumn, Garden of Repose, Cold Nights), 70 above short

\footnotetext{
${ }^{1}$ Unless indicated otherwise, all translations are the authors' (WANG Miao-miao’s).
} 
novels, proses and essays. Besides those works, he has also translated 10 odd masterpieces. The most influential part is his novel creation, especially for the"Youth World", which has become an important part inmodern Chinese literature and has made indispensable significant contributions to the history of modern Chinese Literature.

Among his novels, the Torrent Trilogy comprised of Family, Spring, Autumn is the most influential and successful one. Torrent Trilogy depicts social reality after the May 4th Movement and also criticizes and lashes ruthlessly the feudal ethical code. Beijing Youth Daily (北京青年报) published an article entitled as “The Dusk of an Anarchist” (一个无政府主义者的黄昏) (http://ent.ifeng.com/a/20141125/40375111_0.shtml). In this article the writer wrote: "Ba Jin has finished Family, Spring, Autumn at one stretch, until then the critics find Ba Jin is an anarchist instead of a revolutionary writer.” (巴金一口气又完成了《家》 《春》 《秋》, 评论界这 才发现, 巴金并非“革命作家”, 而是“无政府主义者”). In his novel Torrent Trilogy, Ba Jin described the awakening and rebellion spirit of young intellectuals via creating the character of Jue Hui, Shu Ying, and Jue Min. In his work Family, Ba Jin shows his opposition against Chinese family system and also demonstrates his revolutionary spirit. Ba Jin’s personal experience can be fully demonstrated via Jue Hui in his Family: Young people get together to discuss the social reality and propose the method to solve social problems. They hope to transmit those ideas which have broadened their views. They no longer only pay attention to social and economic questions but to political issues as well. Once they have opportunities, they will discuss the growing discrepancies between the youth and the old authorities. The youth and their peers share the progressive magazines such as New Youth (新青年) and New Tide (新潮). By reading magazines and journals, new ideas can be transmitted freely and shake many old social habits. The revolutionary spirit in the work Family also can be traced in the depiction of women's cutting hair. Traditionally, Chinese women had long braids. At the beginning of 20th century, some young Chinese females began to cut their hair short which is a symbol of breaking with old traditions. The radical magazines and journals encourage women to cut their hair short. In his Family, Ba Jin wrote the discussion about the cutting hair, although the majority of them agreed that idea, few of them wanted to do it. Those brave girls who cut their hair were teased by the outsiders on the street. Because they didn't want to conform to those meaningless traditions, they were rejected by the people. Those descriptions are related to the Russian Anarchist and Russian literature. Those scenarios make people think about the descriptions which Russian writers and revolutionaries wrote. In his Underground Russia, Sergey Stepnyak-Kravchinsky has depicted many populist activities. In the Underground Russia, Sergey Stepnyak-Kravchinsky especially wrote about Sophia Perovskaya and Vera Figner, the two populism leaders. The characters in Ba Jin's book were also originated from these two figures.

Ba Jin was born and lived in a big feudal bureaucrat family and shackled with the arbitrary and monopoly of that kind of family. During the May 4th Movement, he got the anarchism and democracy baptism. Meanwhile, he also took part in the progress organizations and anti-feudal movements, which have provided the reality base and innovation resource for the creation of female characters in his work Torrent Trilogy. By the female self-consciousness and personality creation of Qin and Shu Ying, Ba Jin has raised the social status, bred and nurtured the female with new thoughts. These distinctive characters encourage the young generation to rebel and challenge feudal institution and ethical code. The Torrent Trilogy demonstrates, submission can only be the victim of the feudal institution, he who can rebel can master his own destiny. His works vividly 
demonstrate the significant role played in the awakening on the awareness of the youth thought. Ba Jin has sympathy and grief and indignation on the women who dare not rebel. But he is more hatred towards the old institutions. His pursuit for ideas, aspiration for new life, freedom of personality and rebellious spirit have been placed on the large quantities of young intellectuals, which is also another embodiment of his thoughts value judgment.

\section{The Comparison and Mutual Learning on the Study of Ba Jin in China and the US.}

From the National Library of China—National Digital Library of China (http://www.nlc.gov.cn), American Ba Jin Research scope is more restricted than Chinese counterpart, but there are still more references. To some extent, there are similarities and differences between researches on Ba Jin in Chinaand the US, with certain contributions and significancesto the study of Ba Jin.

\section{(1) Studies on the Personalities of the Characters in Ba Jin's Works}

Since the first publication of the works of Ba Jin, Chinese scholars began to do researches on Ba Jin and his works, especially on the images of characters in them, like Jue Xin, Jue Hui, Zeng Shusheng, Mingfeng, Wang Wenxuan, Du Daxin, etc. in his novels, including Family, Cold Nights, Perish, etc.. And the image of Jue Xin is the main research object running through the work The Torrent Trilogy. Most scholars take Jue Xin as a typical example, who is endowed with twofold characters: coward, or even despaired, with political nonresistance and bow doctrine respectively advocated by Russian writer Leo Tolstoy and Chinese writer Liu Bannong. In Chinese electronic media, the most influential one is On Ba Jin's Novel (论巴金的小说) (<http://www.tebaidu.com/file-ef90a51e4cfebcc19c7040a9b3016ef02348049.html>), which is written by Wang Yao (王瑶). Wang does a study on the image of Jue Xin from the perspective of theoretical criticism, proposing his painful spirit, as the accessory of feudal ethical code. Although he loses the rebellious spirit because of the feudal system, Jue Xin is still full of mixing feelings of love and hate, as well as right and wrong. And it is the same in the study on Ba Jin in the electronic media in the US. The American scholars do an overall and comprehensive analysis on the images of characters in those traditional works of Ba Jin and put forward new opinions and unique insights in an innovative way. Furthermore, the research perspectives are updated, the research methods are increased and the research scopes are becoming more and more extensive and more and more objective.

\section{(2) Studies on Short Stories of Ba Jin}

Ba Jin is practically famous for his novellas and novels. Although his short stories also provide nourishments for the mind, Chinese scholars seldom deviate from the visual field of researchers. So compared to the study on his novellas and prose, the one either on his short stories or specific text analysis are still insufficient. In the Chinese electronic media, the study on Ba Jin's short stories in the early 1980s were politicalized to a certain extent. For example, On the Images of Characters of Ba Jin's Early Novels (巴金早期 短篇小说人物形象漫谈), written by MouShufang (牟淑芳), concludes via analysis:

If a novel has not yet reached the requirements of the times on an ideological level, has not been a good work, but when combined with the history at that time, almost every article is conducive to people in their struggles. So it is good. 
小说在思想水平上, 虽未达到时代所要求的高度, 还不是优秀的作品, 但结合当时的历史看, 它们几乎每一 篇都有利于人民群众的斗争, 因此都是好的。(<http://www.cqvip.com/QK/80416X/198302/1002759654.html>)

On the contrary, the short stories of Ba Jinhave been the main concerns of the American scholars, who are not be restricted by political factors. So they are able to further interpret and analyze the literariness in the short stories of Ba Jin.

\section{(3) Studies on Children'S Literature of Ba Jin}

Ba Jin began to dabble with children's literature when he first read the fairy tales written by Russian poet B.R. Epomehk in 1920s. In the early of 1930s, Ba Jin edited and published his first fairy tales, Happy Boat (幸 福的船). Since 1934, Ba Jin had successively published four fairy tales, including The Immortality Pagoda (长 生塔); The Secret of Tower (塔的秘密); Stable Beads (隐身珠) and A Talking Tree (能言树). In addition, in the 1940s, Ba Jin also translated the fairy tale The Happy Prince from the English writer Oscar Wilde into Chinese. Unfortunately, Ba Jin's children's literature has not been given due attention. Though occasionally, Chinese scholars pay a little attention to the children literature of Ba Jin, they mostly concentrate on the translation or the ideas of his works, or the resonance with the anarchism from the original authors. For instance, On Ba Jin's translation of the Happy Prince and Other Stories from an Aesthetic Perspective (从美学视角看 巴金译<快乐王子及其他故事>), written by Lin Lin (林琳); and An Analysis on Ba Jin'sTranslation of Wilde's Fairy Tales from the Perspective of Translation Aesthetics (从翻译美学析巴金译王尔德童话) written by Liu Xiaoyin (刘孝银), are both critical essays on Ba Jin's translation from the perspective of translation aesthetics. Besides, another essay The Childishness of the Fantasy World- a Comparison on Fairy Tales byB.R.Epomehk and Ba Jin (童话世界里的两颗童心一记爱罗先珂与巴金的童话比较) by Wu Yin (伍寅); analyzes the artistic writing styles by comparing the different views on anarchism and love for human beings respectively from Ba Jin and Epomehk. However, in the study of Ba Jin from the American, there is only one related with the study on Ba Jin's translation of The Happy Prince could be got from Olga Lang: Ba Jin and His Times: Chinese Youth in Transitional Period. But it is pity that it is only mentioned, without further more researches.

\section{(4) Studies on Essays of Ba Jin}

Ba Jin is not only a famous novelist, but also an essayist. He has published 42 essays, and 9 collections. While what the Chinese electronic media mainly focus on are the studies of his novels and biographies, etc. Though there are occasional individual studies on his essays, almost all of them are not as broaden as it should be in both scope and depth. Generally speaking, those studies on essays of Ba Jin can be divided into three phases: (1) In the democratic revolution period; (2) In the following 17 years since the founding of People's Republic of China (PRC, 1949); (3) In the twilight years of Ba Jin. Among them, what have been studied most by the Chinese scholars is Random Thoughts (随想录) which was written by Ba Jin in his twilight years, with over 300 academic research papers.

And what these papers focused on are the ideological contents; moral evaluations; the comparisons on cultures in the West and China; the artistic values; the edition studies; and the narrative analysis, etc. Such as: Rethinking of Thoughts in the Twilights of Ba Jin - Re-read “Random Thoughts” and “Rethinking” (巴金晚年 思想的再思考一一重读<随想录>和<再思录>) by Zeng Shaoyi (曾绍义). On the Personality from the 
Rational Perspective (理性透视下的人格), written by Li Hui (李辉); On the Value of Ba Jin's Random Thoughts and Herzen's Influence on it (论巴金《随想录》的价值及赫尔岑对该书的影响), written by Wang Liming (王立明); Euphemism: the Writing Style in Random Thoughts (<随想录>的“春秋笔法”), written by Luo Siling (罗四鸰) and On the Publication, Edition and the Influence of Ba Jin'sRandom Thoughts (巴金<随 想录>的发表、版本及其反响考述), written by Hu Jingmin (胡景敏). In addition, there are still a certain studies holding critical views of Random Thoughts, with Bao Yanbing (包雁冰), Lin Xianzhi (林贤治) and Zhang Fang (张放) as representatives. For instance, On the Comments of Random Thoughts (关于<随想录>评 价的思考), written by Zhang Fang. Although the studies on the essays of Ba Jinare limited, the studies in the US. are rather onefold, which is even so restricted to the studies of Random Thoughts that it could only be used as an introductory reading materials about Ba Jin's essays.

Therefore, the study on Ba Jin in Chinese electronic media is not as perfect as it should be, but even with some problems. However, it is still incomparable when being compared with the one in the US-American electronic media, either in the scope or depth. Generally speaking, the reports on Ba Jin in Chinese electronic media have involved with almost every relevant aspect, with more on some aspect, or less on the other one. So the study still covers broaden ranges.

Different from those in the Chinese electronic media, the study on Ba Jin in the US-American media, mainly focuses on Ba Jin's masterpieces and his thoughts. For his masterpiece, Family is the main concern, with regards to his other works or the essay Random Thoughts, which was written in Ba Jin's twilight years. And for his thoughts, anarchism is the most important topic, even with noinvolvement intheactivities in translation, editing and publishing, as well as his relationship with Esperanto. But through the analysis and re-research on the study of Ba Jinin the US-American media, it contributes certain enlightenments and significances to the Chinese study of Ba Jin. However, no matter focusing on anarchism, the Russian populism or Chinese traditional cultures and new literary ideas in the aspect of thoughts and standpoints, the study of Ba Jinfrom the US-American media, always tries to play down the political significances and strengthen its literary values. On the whole, American scholars usually introduce more on the basic information on Ba Jin, including his life story, his writing style, the contents of his novels, etc, but less comments on political significances Ba Jin and his works have contributed. In addition, they also follow with interest on the influence on Ba Jin's thoughts by the Chinese traditional cultures and new literary ideas on Ba Jin. At the same time, they restore Ba Jin to his original life with the simple life, public attitude, and kindness as an individual, trying to narrow the gaps between readers and him, in order to arouse their concerns and interests. Therefore, there are many reasons on the differences on studies of Ba Jin in Chinese and American. But the most important one must be not only the objective historical reasons,but also the inherent subjective reasons; not only the influence from cultural factors, but also the impact from institutional factors.

\section{Conclusion}

In conclusion, the study of $\mathrm{Ba}$ Jin in Chinese electronic media takes literariness as the core and reflects the cognition of Ba Jin, in the contemporary civil society. Meanwhile, it also shows the far-reaching influence that Ba Jin has given for the Chinesecontemporary society and literature. This paper aims to provide a useful reference for the survey and study on the transmission and reception of $\mathrm{Ba}$ Jin in China electronic media, 
expecting to contribute to the study of Ba Jin home and abroad. In addition, it is advocated that the studies of Ba Jin in both Chinese and US-American electronic media, as well as the literary and cultural exchanges, must be based on the national researches, with references from those from the overseas. Meanwhile, it is also advocated: "to build a beautiful and harmonious world on human civilization, with proposes in exchanges and mutual learning from different countries; with proposes in the excellent civilizing achievements from different ethnic groups; by overcoming the shortcomings and then acquiring the strong points from others.” (“倡导交流 互鉴，注重汲取不同国家、不同民族创造的优秀文明成果，取长补短，兼收并蓄，共同绘就人类文明 美好画卷。”) (Xi Jinping, <http://www.wenming.cn/djw/gcsy/yw/201605/t20160520_3372088.shtml>)

\section{References}

Baidu (百度). <wwww.baidu.com>

Baidu academic website 百 学 度 术 <http://xueshu.baidu.com/s?wd=paperuri:(4554c814ed0a22a61f45802c889aac20)\&filter=sc_long_sign\&sc_ks_para=q\%3D 巴金先生简历\&tn=SE_baiduxueshu_c1gjeupa\&ie=utf-8\&sc_us=6406463985443579767?

Baidu Encyclopedia $\quad$ 百 $\quad$ 度 $\quad$ 百 <http://baike.baidu.com/link?url=bU_Z9-x7ceIlYsqCdZ7kQDq0d4G3kCwd4pjvH_FlwSrGN--vhyFDrcnpXH_eENx_VqsZ NgOo4pHoHnh-gSJYUK>

Baidu Encyclopedia ( 百 度 $\quad$ 百 <http://baike.baidu.com/link?url=KXRJKs_l3xnXo8RnyNH3I7ELvGG-PR87I9QnJ70GdObAn2Nowc3umTYwKsgQEbzpE k4Mdx35yZwEwrUj4Ghr8>

Baidu Encyclopedia (百度百科). <http://baike.baidu.com/view/1717.htm>

Baidu homework assistance (百度作业帮). <http://www.zybang.com/question/3dd2b626f170aefaec3e6e827247b7ad.html>

Baidu to know ( 百 度 <http://zhidao.baidu.com/link?url=5q9Ur67nJnrGWVGIJ25Dftj5DiCiK2MrD_HWJTUw4I8LNpe-u5R9ELBhdgb_kJmlYIv FG2NS0hdNPDwGc5ACGWfVPXGiGOEVfaftZR0-Xmq

Baidu to Know ( 百 度 知 <http://zhidao.baidu.com/link?url=ndrsCYtXYhq_D43H1zsLfKy1H7Ouya7qSgpAV7fEJ3ldoQ6YDgP02YuHUv-83idfxRG NWSDQQCv1z5khfIs4Hq>

Beijing Youth Daily (北京青年报) <http://ent.ifeng.com/a/20141125/40375111_0.shtml>

CHEN, D. C. (陈丹晨). (1981). 巴金评传 (Critical Biography on Ba Jin). Shi Jiazhuang: Hebei People’s Press.

CHEN, S. H. (陈思和). (1992). 人格的发展：巴金传 (Development of Personality: Biography of Ba Jin). Shanghai: Shanghai People's Press.

China Social Science Network (中国社会科学网). <http://www.cssn.cn/wx/wx_xdwx/201509/t20150923_2469084.shtml>

de Zepetnek, T., \& Boruszko, G. (2003). New work about world literatures. Retrieved from http://stateofthediscipline.acla.org/entry/paradigm-shift-comparative-humanities-digital-humanitiespedagogy-new-media-tec hnology-and

Hayles, N. K. (2007). Electronic literature: What is it. Retrieved from http://eliterature.org/pad/elp.html

Hockx, M. (2015). Internet literature in China. New York: Columbia UP.

LI, C. G. (李存光). (1994). 作家传 (The Biography of Ba Jin). Beijing: Shi Yue Literature and Art Press.

LIN, L. (林琳). (2007). 从美学视角看巴金译<快乐王子及其他故事 (On Ba Jin’s translation of the Happy Prince and Other Stories from an Aesthetic Perspective). Shanghai: Shanghai International Studies University.

LIU, X. Y. (刘孝银). (2012). 从翻译美学析巴金译王尔德童话 (An Analysis on Ba Jin’s Translation of Wilde’s Fairy Tales from the Perspective of Translation Aesthetics ). Taiyuan: Shanxi Normal University.

Monsterleet, J. (Ming Xingli). (1950). 巴金的生活和著作 (Ba Jin’s Life and Works). Shanghai: Shanghai Wen Feng Press.

MOU, S. F. (牟淑芳). (1983). 巴金早期短篇小说人物形象漫谈 (On the Images of Characters of Ba Jin’s Early Novels). Retrieved from http://www.cqvip.com/QK/80416X/198302/1002759654.html 
NetEase news center (网易新闻中心). <http://news.163.com/11/1120/15/7JAJ9C3U00014AEE.html\#from=relevant>

OUYANG, Y. Q. (欧阳友权). (2003). 网络文学论纲 (The outline of Network Literature) (p. 412). Beijing: People’s Literature Press.

Sina news center (百度新闻中心). <http://news.sina.com.cn/c/2005-10-18/08457196338s.shtml>

Sohu news column (百度新闻专栏). <http://news.sohu.com/20121128/n358933331.shtml>

The celebrities' proverbs website (名人名言网) <http://www.mrzl.com/mrjs/wenhua/200602/mrjs_223.html>

The celebrities’ resumes website (名人简历网) <http://www.gerenjianli.com/Mingren/01/lmkrd2bkdk9spsi.html>

The celebrities' website (名人网). <http://www.23yy.com/190000/188703.shtml>

WANG, Y. (王瑶). (1957). 论 巴金的小 说 (On Ba Jin’s Novel). Retrieved from http://www.tebaidu.com/file-ef90a51e4cfebcc19c7040a9b3016ef02348049.html

WU, Y. (伍寅). (2014). 童话世界里的两颗童心七记爱罗先珂与巴金的童话比较 (The Childishness of the Fantasy World- a Comparison on Fairy Tales by B. R. Epomehk and Ba Jin). 梧州学院学报(Journal of Wuzhou University).

XI, J. P. (习近平). (2016). 习近平：在哲学社会科学工作座谈会上的讲话 (2016年5月17日). Retrieved from http://www.wenming.cn/djw/gcsy/yw/201605/t20160520_3372088.shtml

YU, S. M. (余思牧). (1964). 作家巴金 (Author Ba Jin). Hong Kong: Southern China Press. 